\title{
Síntesis y propiedades de filmes basados en quitosano/lactosuero
}

\section{Synthesis and film properties of chitosan and whey}

\author{
Richar Blanquicet Macea1, Carlos Flórez De Hoyos', Yina González Montes', \\ Edgardo Meza Fuentes ${ }^{2}$ y Johana Inés Rodríguez Ruiz ${ }^{3 *}$ \\ ${ }^{1}$ Departamento de Biología, Universidad de Sucre, Sincelejo, Sucre, Colombia \\ ${ }^{2}$ Grupo de Estudios en Materiales y Combustibles, Facultad de Ciencias Exactas y Naturales, \\ Universidad de Cartagena, Cartagena de Indias, Bolívar, Colombia \\ ${ }^{3}$ Grupo de Investigación en Procesos de la Industria Petroquímica, Centro para la Industria \\ Petroquímica SENA, Regional Bolívar, Cartagena de Indias, Bolívar, Colombia
}

*ji.rodriguez@misena.edu.co

\begin{abstract}
Resumen
El quitosano es un polímero natural derivado de la desacetilación de la quitina con propiedades tales como biocompatibilidad, biodegradabilidad y formación de filmes, de gran aplicación en el campo de la industria, alimentación y medicina. Los filmes a base de quitosano y lactosuero fueron preparados teniendo en cuenta la concentración de la solución de quitosano $(1 ; 1.5$ y $2 \% \mathrm{v} / \mathrm{v})$, la relación en volumen de lactosuero $(4: 20,6: 20$ y 8:20 v/v) y el tiempo de secado de 4.5, 5.0 y 5.5 horas. Estas condiciones de preparación se optimizaron empleando la metodología de la superficie de respuesta. La quitina extraída previamente de los exoesqueletos de camarón fue tratada con una solución acuosa de $\mathrm{NaOH}$ al $50 \%$ en masa, hasta obtener quitosano con un grado de desacetilación de $80.72 \%$. El quitosano obtenido fue disuelto en ácido acético para obtener las distintas soluciones que posteriormente fueron combinadas con lactosuero. Los filmes sintetizados fueron caracterizados por espectroscopia en la región del infrarrojo y se evaluaron los parámetros de espesor, densidad, solubilidad, transparencia, hinchamiento y degradación. La degradación de los filmes quitosano/lactosuero disminuye con el aumento de la concentración de quitosano. El porcentaje de hinchamiento de los filmes se ve afectado por las proporciones de lactosuero. La concentración de lactosuero incide en el aumento del espesor y la densidad de los filmes.
\end{abstract}

Palabras-clave: quitosano, lactosuero, filme, solubilidad, degradación.

\begin{abstract}
Chitosan is a natural polymer derived from deacetylation of chitin, which exhibits properties such as biocompatibility, biodegradability and may form films, being applied in the food industry and medicine. Degradable chitosan films were prepared from chitosan extracted from shrimp shells and whey, using different concentrations of chitosan solution (1, 1.5, and $2 \% \mathrm{v} / \mathrm{v})$, with $(4: 20,6: 20$ and $8: 20 \mathrm{v} / \mathrm{v})$ whey proportions, for $4.5,5.0$ and $5.5 \mathrm{~h}$ at $60^{\circ} \mathrm{C}$. Chitin extracted previously from shrimp shells was treated with a solution of $50 \%$ of $\mathrm{NaOH}$ to obtain chitosan with $80.72 \%$ deacetylation degree. This chitosan was dissolved in $1 \%(\mathrm{v} / \mathrm{v})$ acetic acid, leading to the solutions that were then combined with whey. The films were characterized with infrared spectroscopy, and had thickness, density, solubility, transparency, swelling and degradability evaluated. The solubility and degradability of chitosan/whey films decreased with increasing chitosan concentration. The proportion of lactic serum affects the film swelling, and the thickness and density increased with whey relative concentration.
\end{abstract}

Keywords: chitosan, whey, films, solubility, degradation.

\section{Introducción}

En el mundo, son numerosos los esfuerzos que se realizan para disminuir el uso e impacto ambiental de los plásticos derivados de petróleo, por lo cual se han incrementado las investigaciones dirigidas a obtener materiales biodegradables. Aunque no se pretende el reemplazo total de los derivados del petróleo, se tiene el potencial de reducir considerablemente estos materiales ${ }^{[1,2]}$.
Los materiales empleados para la formación de filmes y recubrimientos biodegradables están constituidos principalmente de proteínas, lípidos, y polisacáridos. Incluyendo los que son a base de celulosa, quitosano, almidones, dextrinas, alginatos y pectinas. Entre los materiales producidos a partir de desechos de la industria de alimentos que se pueden usar para la elaboración de 
filmes está el quitosano, el cual puede ser usado para el recubrimiento e empaques de alimentos tales como las frutas y otros vegetales ${ }^{[3]}$.

El quitosano es un poliaminosacarido producido por la N-desacetilación de la quitina, este material exhibe propiedades físicoquímicas únicas; es biocompatibible, no toxico, y además es biodegradable, lo que ha generado un interés potencial para su uso en recubrimientos comestibles. Además de estas propiedades los filmes de quitosano actúan como de barrera al oxígeno y poseen actividad bactericida y fungicida contra algunos patógenos de frutos. Sin embargo, por su carácter hidrofílico, el quitosano requiere la presencia de aditivos para generar o incrementar su hidrofobicidad, al tiempo en que se busca mejorar sus propiedades mecánicas $^{[4]}$.

En los últimos años se han preparado mezclas de quitosano con diferentes polímeros como almidón, alcohol polivinílico, celulosa y sus derivados ${ }^{[4]}$. Estos filmes presentan una baja barrera contra la humedad y son frecuentemente solubles en agua, reduciendo el uso potencial en aplicaciones alimenticias por lo que algunos autores han usado aditivos plastificantes como el sorbitol, glicerol y etilenglicol, con el fin de disminuir no solo su carácter hidrofílico, sino también con la intención de obtener filmes más flexibles y extensibles ${ }^{[4]}$.

Un limitante en el uso de aditivos para mejorar las propiedades de los filmes de quitosano, es el valor de estos, por lo que el uso de material residual o de bajo valor comercial es necesario para la posible aplicación comercial de los filmes de quitosano. Un material que normalmente es desechado por la industria de lácteos es el lactosuero, el cual es uno de los materiales más contaminantes que existen en la industria alimentaria, pero que al mismo tiempo puede ser usado para la síntesis de polímeros biodegradables. Este residuo industrial contiene más del $25 \%$ de las proteínas de la leche, cerca del $8 \%$ de la materia grasa y cerca del $95 \%$ de la lactosa, sustancias que son esenciales en la síntesis de biopolímeros $^{[5]}$.

En este trabajo se sintetizaron filmes degradables a base de quitosano extraído de exoesqueletos de camarón, y de lactosuero. De igual forma se evaluaron algunas de sus propiedades y su nivel de degradación en agua.

\section{Procedimiento Experimental}

\subsection{Obtención del quitosano}

Para la obtención de la quitina (precursora del quitosano) se realizó inicialmente la separación de los caparazones de residuos de camarón obtenidos de una industria camaronera del municipio de Coveñas (Sucre, Colombia). Los caparazones fueron lavados con agua destilada para eliminar los residuos e impurezas y posteriormente secados al sol durante $8 \mathrm{~h}$. Seguidamente el material seco se sometió a un proceso de desmineralización con una solución $2.0 \mathrm{M}$ de $\mathrm{HCl}$ a $30^{\circ} \mathrm{C}$ durante $2 \mathrm{~h}$. Posterior a la desmineralización, el material seco fue sometido a un proceso de desproteinización con una solución de $0.1 \mathrm{M}$ de $\mathrm{NaOH}$ a $80^{\circ} \mathrm{C}$ durante $1 \mathrm{~h}$ bajo agitación constante, repitiendo este mismo procedimiento por triplicado.
La quitina así obtenida fue secada y sometida a un proceso de desacetilación con una solución acuosa al $50 \%$ en masa de $\mathrm{NaOH}$ a $105^{\circ} \mathrm{C}$, manteniendo el sistema en reflujo y bajo agitación constante durante $24 \mathrm{~h}$ para la obtención el quitosano.

En cada una de las etapas del proceso, los productos obtenidos fueron lavados con abundante agua destilada hasta un obtener $\mathrm{pH}$ neutro en el agua posterior al lavado y secados al sol durante $8 \mathrm{~h}^{[6]}$.

\subsection{Obtención del lactosuero}

El lactosuero se obtuvo de una fuente local de la ciudad de Sincelejo-Colombia, productora de suero y de queso para la venta. Este material fue sometido a un proceso de esterilización en autoclave durante $1 \mathrm{~h}$ a $100{ }^{\circ} \mathrm{C}$ y conservado bajo refrigeración hasta su utilización.

\subsection{Obtención de los filmes quitosano/lactosuero}

Se prepararon soluciones de quitosano al 1\%, 1.5\% y $2 \%(\mathrm{p} / \mathrm{v})$ en una solución de ácido acético al $1 \% \mathrm{v} / \mathrm{v}$. En todos los casos la muestra se disolvió a $60^{\circ} \mathrm{C}$ con agitación constante, posteriormente las soluciones resultantes fueron filtradas para retirar las impurezas insolubles y las soluciones se dejaron reposar a temperatura ambiente hasta la desaparición de burbujas visibles.

Para la formación de los filmes quitosano/lactosuero se realizaron combinaciones de las soluciones base de quitosano $(1 \%, 1.5 \%$ y $2 \% \mathrm{p} / \mathrm{v})$ con volúmenes de lactosuero en proporciones de 4:20, 6:20, 8:20 (ml lactosuero: $\mathrm{ml}$ de solución final), las proporciones fueron expresadas como 20,30, y $40(\% \mathrm{v} / \mathrm{v})$ respectivamente; y sometidas a secado en periodos de $4.5,5$ y 5.5 horas, para evaluar un total de 27 tratamientos con 3 repeticiones (Tablas 1 y 2), usando un diseño factorial $3^{3}$. Posteriormente $20 \mathrm{~mL}$ de las soluciones de quitosano/lactosuero fueron vertidas en cajas acrílicas de Petri de $9 \mathrm{~cm}$ de diámetro y secadas a $60^{\circ} \mathrm{C}$, seguidamente se desmoldaron los filmes por desprendimiento del acrílico.

\subsection{Caracterización del quitosano}

Al quitosano obtenido inicialmente se le determinó el grado de desacetilación por espectrofotometría de infrarrojo con transformada de Fourier (FTIR), utilizando un espectrofotómetro de FTIR marca SHIMADZU modelo 84005 a través de la dispersión de una pequeña porción de la muestra en $\mathrm{KBr}$, usando una relación 1:100 (muestra:KBr), para esta medida se utilizaron las absorbancias de $1645 \mathrm{~cm}^{-1}$ y $3456 \mathrm{~cm}^{-1}$ correspondientes a la banda amida I útil en la medida del contenido del grupo $\mathrm{N}$-acetilo y del grupo hidroxilo respectivamente, utilizando el método propuesto por Baxter et al. ${ }^{[7]}$ para el cálculo del grado de acetilación (GA) a través de la Ecuación 1, que usa la relación de las absorbancias $\left(\mathrm{A}_{1645} / \mathrm{A}_{3456}\right)$, el valor de 115 corresponde al reciproco de la pendiente de la curva lineal de la relación de las absorbancias versus el grado de acetilación.

$$
G A=\left[\left(\frac{A_{1645}}{A_{3456}}\right) \times 115\right]
$$


Tabla 1. Diseño factorial $3^{3}$

\begin{tabular}{cccc}
\hline \multirow{2}{*}{ Factores } & \multicolumn{3}{c}{ Niveles } \\
\cline { 2 - 4 } & $\mathbf{- 1}$ & $\mathbf{0}$ & $\mathbf{1}$ \\
\hline [ ] Quitosano (\%) & 1 & 1.5 & 2 \\
Prop. Lactosuero (ml) & $4: 20(20)$ & $6: 20(30)$ & $8: 20(40)$ \\
Tiempo (horas) & 4.5 & 5 & 5.5 \\
\hline
\end{tabular}

Tabla 2. Combinaciones de los factores.

\begin{tabular}{|c|c|c|c|}
\hline Muestra & [] quitosano & $\begin{array}{c}\text { Prop. } \\
\text { lactosuero }\end{array}$ & Tiempo \\
\hline 1 & -1 & -1 & -1 \\
\hline 2 & -1 & -1 & 0 \\
\hline 3 & -1 & -1 & 1 \\
\hline 4 & -1 & 0 & -1 \\
\hline 5 & -1 & 0 & 0 \\
\hline 6 & -1 & 0 & 1 \\
\hline 7 & -1 & 1 & -1 \\
\hline 8 & -1 & 1 & 0 \\
\hline 9 & -1 & 1 & 1 \\
\hline 10 & 0 & -1 & -1 \\
\hline 11 & 0 & -1 & 0 \\
\hline 12 & 0 & -1 & 1 \\
\hline 13 & 0 & 0 & -1 \\
\hline 14 & 0 & 0 & 0 \\
\hline 15 & 0 & 0 & 1 \\
\hline 16 & 0 & 1 & -1 \\
\hline 17 & 0 & 1 & 0 \\
\hline 18 & 0 & 1 & 1 \\
\hline 19 & 1 & -1 & -1 \\
\hline 20 & 1 & -1 & 0 \\
\hline 21 & 1 & -1 & 1 \\
\hline 22 & 1 & 0 & -1 \\
\hline 23 & 1 & 0 & 0 \\
\hline 24 & 1 & 0 & 1 \\
\hline 25 & 1 & 1 & -1 \\
\hline 26 & 1 & 1 & 0 \\
\hline 27 & 1 & 1 & 1 \\
\hline
\end{tabular}

\subsection{Caracterización del lactosuero}

$\mathrm{Al}$ lactosuero se le determinó el $\mathrm{pH}$ utilizando un $\mathrm{pH}$ metro marca Metrohm modelo 826/827, el contenido de nitrógeno fue determinado usando el método Kjeldhal, usando una unidad de digestión Kjeldahl marca BUCHI modelo K-424 y la Ecuación 2, los valores de 0.1, 0.0014 corresponden a la normalidad del ácido y al peso del miliequivalente de nitrógeno, respectivamente.

$$
\% \text { Nitrógeno }=\frac{\left(\begin{array}{c}
\text { Volácido gastado- } \\
\text { vol.blanco }
\end{array}\right)}{\text { gdemuestra }} \times 0.1 \times 0.0014 \times 100 \%
$$

Para convertir el porcentaje de nitrógeno en proteína se utilizó el factor de proteína típico para leche de 6.30 .

\subsection{Caracterización de los filmes de quitosano/ lactosuero}

A los filmes de quitosano/lactosuero se le realizaron estudios por espectroscopia en la región de infrarrojo (FTIR) y se determinaron los parámetros de espesor, densidad, transparencia, solubilidad, hinchamiento y degradación. El análisis de los resultados a partir de los parámetros usados se realizó a través de superficies de respuesta obtenidas del uso del diseño factorial $3^{3}$, usado en la síntesis de los filmes, en la cual las variables fueron; concentración de soluciones de lactosuero $(1 \%, 1.5 \%$ y $2 \% \mathrm{p} / \mathrm{v})$, proporción quitosano/lactosuero $(0.2,0.3,0.4)$ y tiempo de secado $(4.5,5.0,5.5 \mathrm{~h})$, correspondientes a los valores mostrados en la Tabla 1.

Los estudios por espectroscopia infrarroja se realizaron en espectrofotómetro de FTIR marca Shimadzu modelo 84005 en la región de 4000 a $400 \mathrm{~cm}^{-1}$. En este análisis se colocaron directamente los filmes de quitosano en una celda para medida directa de transmitancia en el equipo.

Para la medida de espesor y densidad se utilizó un micrómetro de puntas SUHL/DDR con una resolución de $0.001 \mathrm{~mm}$. El espesor de cada filme se midió en 10 puntos diferentes a temperatura ambiente, considerando la media de los valores como su espesor ${ }^{[3]}$. Luego se determinó en una balanza analítica el peso de cada filme con medidas de aproximadamente $1.5 \mathrm{~cm}^{2}$ y se calculó el volumen de dicha muestra para hallar la densidad respectiva, usando un promedio de 3 mediciones para cada muestra ${ }^{[3]}$. La solubilidad en agua de los filmes expresada en términos de masa soluble $(\% \mathrm{~ms})$ fue realizada por triplicado y se determinó según el método propuesto por Gontard ${ }^{[8]}$ con algunas modificaciones. Estos resultados de solubilidad en agua de las películas podrían ser utilizados para estimar la velocidad a la que podrían disolver si se expone a una ambiente húmedo durante una aplicación específica ${ }^{[9]}$ para esto se utilizaron muestras de $1 \mathrm{~cm}^{2}$ de área, que fueron pesadas inicialmente y se sumergieron en recipientes con $10 \mathrm{ml}$ de agua destilada durante un periodo de 24 horas a temperatura ambiente. Seguidamente, las muestras se secaron a $60^{\circ} \mathrm{C}$ para determinar el peso seco final de la muestra. La solubilidad se expresó en términos de masa soluble (MS) de acuerdo con la Ecuación $3^{[4]}$.

$$
\% M S=\left(\frac{W_{I}-W_{F}}{W_{I}}\right) \times 100 \%
$$

Donde $\mathrm{W}_{\mathrm{I}}$ y $\mathrm{W}_{\mathrm{F}}$ corresponden al peso inicial y final respectivamente.

La capacidad de absorción o de hinchamiento $\left(\mathrm{W}_{\mathrm{Sw}}\right)$ de los filmes de quitosano se midió a temperatura ambiente en una disolución de un buffer de fosfato salino (PBS), una solución amortiguadora de $\mathrm{pH}$ comúnmente empleada para procedimientos bioquímicos. Su osmolaridad y concentración de iones (Cl-, $\mathrm{Na}+\mathrm{y} \mathrm{K}+$ ) es muy semejante a la del líquido extracelular de los mamíferos. Visando que los filmes de quitosano lactosuero preparados sean comestibles. Se utilizaron muestras $1 \mathrm{~cm}^{2}$, previamente pesadas y colocadas en recipientes con $10 \mathrm{ml}$ de PBS por 30 minutos. El peso húmedo de los filmes se determinó por el porcentaje absorbido en la superficie de las muestras, secando el exceso de agua con papel filtro, posteriormente los sólidos fueron pesados y el porcentaje de absorción de agua en el medio se calculó utilizando la Ecuación $4^{[10]}$. 


$$
W_{s w}=\left(\frac{W_{30-} W_{0}}{W_{0}}\right) x 100
$$

Donde $\mathrm{W}_{30}$ y $\mathrm{W}_{0}$ corresponden al peso después de 30 y 0 minutos de tratamiento con la solución de PBS, respectivamente.

El análisis de degradación (\%Degradación) se realizó mediante modificación de la norma técnica colombiana NTC $1027^{[11]}$. Norma técnica por la cual se determinan los efectos de productos químicos líquidos, incluyendo el agua en los materiales plásticos. Se cortaron muestras de cada filme $(1.5 \times 1.5 \mathrm{~cm})$ las cuales previamente se pesaron y luego se sumergieron en frascos con $10 \mathrm{ml}$ de agua destilada cada uno. Las muestras se expusieron al agua durante un periodo total de 45 días, y se monitoreó la diferencia de peso cada 15 días. Para esto las muestras se lavaron con agua destilada y se secaron en horno a $50^{\circ} \mathrm{C}$ por 2 horas. El porcentaje de degradación se evaluó por la diferencia de peso del filme antes y después del ensayo utilizando la Ecuación 5, donde $\mathrm{W}_{\mathrm{I}} \mathrm{y} \mathrm{W}_{\mathrm{F}}$ corresponden al peso inicial y final respectivamente.

$$
\% \text { Degradación }=\frac{W_{I}-W_{F}}{W_{I}} \times 100
$$

\section{Resultados y Discusión}

\subsection{Materiales de partida}

El quitosano obtenido mostró una apariencia blanca debido a las múltiples exposiciones al sol a la que fue sometida la materia prima durante su proceso de obtención y purificación. Los rayos solares, por causa de radiación ultravioleta, son capaces de eliminar por procesos de degradación oxidativa a los dobles enlaces de C-C presentes en los pigmentos carotenoides como la astaxantina y el $\beta$-caroteno que se encuentran en la quitina y el quitosano.

El grado de desacetilación del quitosano extraído fue de $80.72 \%$. Este alto porcentaje de desacetilación obtenido indica una gran remoción de grupos acetilo en la estructura de la quitina extraída, así como también la gran cantidad de grupos aminos libres en el quitosano y permite. En el espectro FTIR del quitosano (Figura 1) se observan las bandas de los grupos funciónales característicos de la molécula de quitosano. Se aprecian las bandas correspondientes a los estiramientos $\mathrm{O}-\mathrm{H}$ y N-H $\left(3.250-3.600 \mathrm{~cm}^{-1}\right)$, característicos de alcoholes, aminas y amidas presentes en la estructura del solido desacetilado. Se observa que esta banda está centrada en $3456 \mathrm{~cm}^{-1}$ producto de la sobreposición de las bandas originadas por los alargamientos y tensiones de los grupos $\mathrm{O}-\mathrm{H}$ y N-H presentes ${ }^{[12]}$. En el espectro se observan también bandas del estiramiento $\mathrm{C}-\mathrm{H}$ a $2842 \mathrm{~cm}^{-1}$ y otras originadas por estiramientos $\mathrm{C}=\mathrm{O}$ y N-H, característicos de grupos amido, entre $1.650-1.550 \mathrm{~cm}^{-1}$. La banda característica a $1645 \mathrm{~cm}^{-1}$ se relaciona con el grupo $\mathrm{C}=\mathrm{O}$ presente en un grupo amido (I) y la asignada a $1432 \mathrm{~cm}^{-1}$ se debe a un grupo amido (II). La banda de absorción relativa a deformaciones del grupo amino se observa a $1565 \mathrm{~cm}^{-1}$, mientras que la banda centrada en $1367 \mathrm{~cm}^{-1}$ surge de vibraciones del estiramiento del grupo metil $(\mathrm{C}-\mathrm{H})$ presente en el grupo acetamido ( $\mathrm{R}-\mathrm{NHCOCH}_{3}$ ) residual (19.28\%), que está allí debido a la desacetilación incompleta de la quitina ${ }^{[12]}$, o debido a grupos O-H unidos a los anillos. La banda observada a $1081 \mathrm{~cm}^{-1}$ se debe a la presencia del grupo piranósico.

En relación al lactosuero usado, el contenido de proteína obtenido fue de $0.61 \%$. Este resultado se encuentra dentro del intervalo de concentración proteínica en lactosuero, que oscila de $0.2 \%$ a $1.1 \%{ }^{[13]}$. El $\mathrm{pH}$ de este material es de 4.0; valor característico de lactosueros provenientes de la fabricación de quesos y que depende del proceso de cuajado de éstos.

\subsubsection{Filmes de quitosano/lactosuero}

Los filmes obtenidos a partir de quitosano/lactosuero (Figura 2) mostraron una apariencia amarilla, compacta y brillante (Figuras 2a, b). Los filmes obtenidos presentaron algunas rugosidades relacionadas al efecto de la protonación incompleta de los grupos aminos interiores con el ácido acético presente en el medio durante la síntesis producen las rugosidades en los filmes, además de la interacción con el material acrílico de la placa de Petri (Figura 2c).

Durante el secado, el ácido acético se evaporó más rápidamente que el agua, conduciendo a cambios en el pH del disolvente que podría inducir la separación de fase entre los solutos. Según Ferreira, cuando se preparan películas a $\mathrm{pH}>6.5$ se forman películas heterogéneas y el fenómeno de separación de fases se describe como un resultado de la incompatibilidad entre la proteína de suero de leche y el quitosano ${ }^{[14,15]}$

La interacción entre el ácido acético y el quitosano en el momento de elaboración de la lámina para el análisis formó un acetato de quitosano ${ }^{[16]}$, esta reacción aporta un cambio de los picos de los grupos funcionales como se observa en los espectros FTIR (Figuras 3-5); en general los espectros de infrarrojo de los filmes obtenidos mostraron la banda correspondiente a la vibración O-H entre $3500-3200 \mathrm{~cm}^{-1}$. El pico a $2831 \mathrm{~cm}^{-1}$ se asigna al estiramiento vibracional típico del enlace $\mathrm{C}-\mathrm{H}^{[17]}$ y el pico localizado a $1691 \mathrm{~cm}-1 \mathrm{se}$ debe al estiramiento $\mathrm{C}=\mathrm{O}$ (amida $\mathrm{I}$ ).

La presencia de proteínas de lactosuero origina una disminución en la transmitancia en todo el espectro; principalmente en el intervalo de 2750 - $3613 \mathrm{~cm}-1$ (donde también absorben enlaces $\mathrm{C}$-H de ácidos grasos y grupos metilos) y $1250-1750 \mathrm{~cm}-1$ (amidas) ${ }^{[12]}$ y una elongación bastante pronunciada en estas regiones.

El espesor de los filmes influye significativamente sobre las propiedades de los mismos. Sin embargo, esto no ha sido extensivamente estudiado a pesar de que se plantea que el control del mismo es necesario por su influencia sobre la mayoría de las propiedades de los filmes, y para la comparación entre estas. Se ha reportado influencia del espesor sobre las propiedades de transporte y mecánicas de las filmes ${ }^{[18]}$. El espesor influye sobre la permeabilidad al vapor de agua de los filmes y cubiertas biodegradables hidrofílicas. La influencia del espesor sobre las propiedades ópticas también ha sido estudiada. Filmes obtenidos a partir 


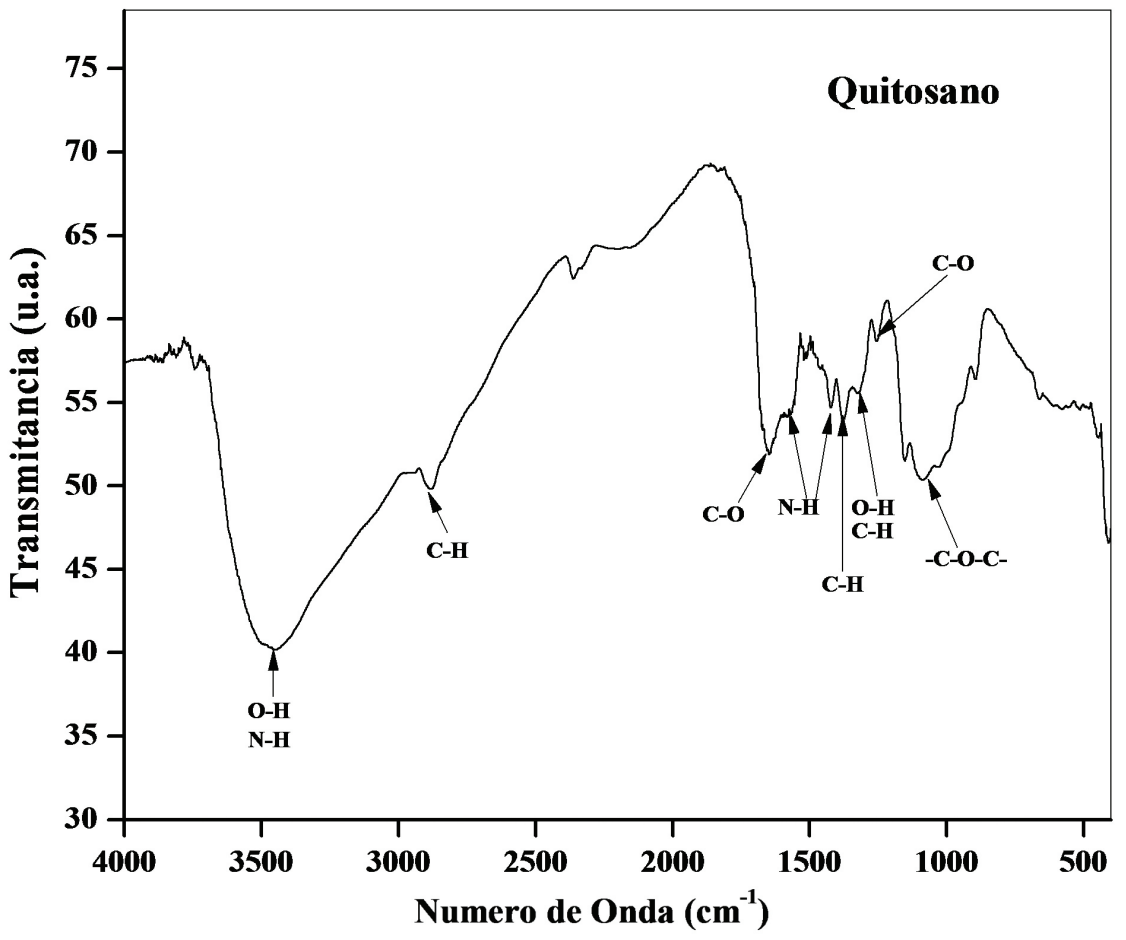

Figura 1. Espectro del quitosano obtenido por la desacetilación de la quitina.

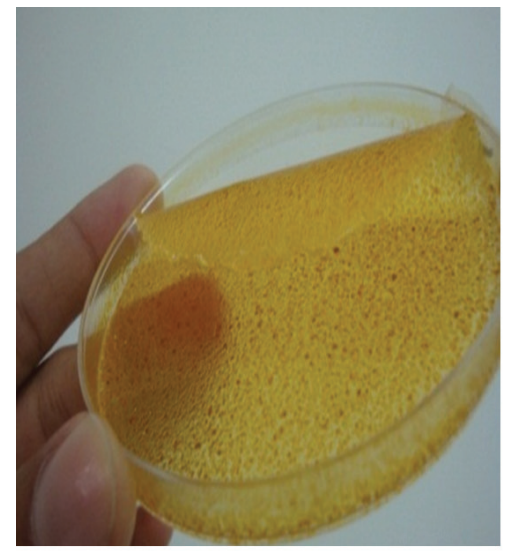

(a)

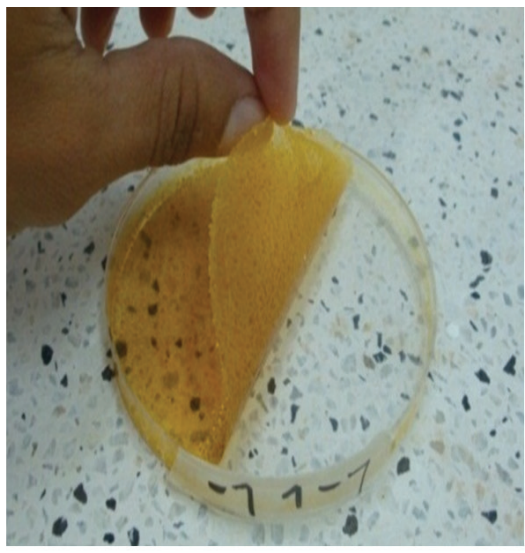

(b)

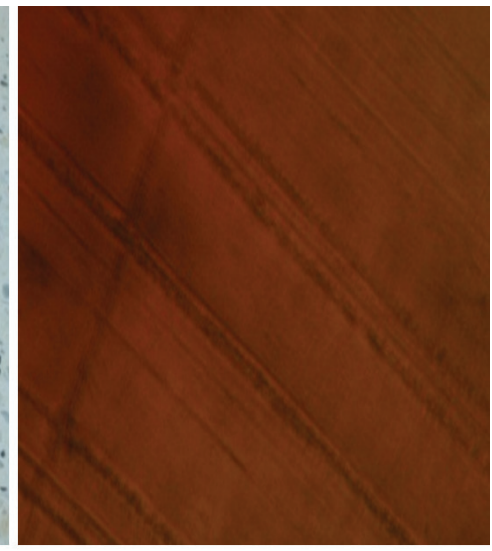

(c)

Figura 2. Aspecto visual de los filmes quitosano/lactosuero. a) Filmes adheridos a las placas de petri. b) Desmoldado del filme. c) Rugosidades o estrías en los filmes.

de quitosano mostraron una apariencia ligeramente amarilla, oscureciéndose el color a medida que el espesor aumentó ${ }^{[19]}$.

En la Figura 6 se muestra la dependencia del espesor (Figuras 6a, c) y de la densidad (Figuras 6d, f) de los filmes en función de la proporción de lactosuero (\%) y de quitosano empleados en las síntesis. Se observa que mayores cantidades de lactosuero conduce a la producción de filmes con mayor espesor y densidad. En los filmes secados durante 4.5 y $5.0 \mathrm{~h}$ el espesor de los filmes aumentó con la concentración de las soluciones de lactosuero usadas y con el aumento de la concentración de las soluciones de quitosano de 1 al 1.5\%.
En el caso de los sólidos obtenidos al secar durante $5.5 \mathrm{~h}$, se obtuvieron los filmes con mayor espesor, consiguiéndose obtener laminas con $0.19 \mathrm{~mm}$ de espesor. En estos materiales secos por $5.5 \mathrm{~h}$ se observó que en las soluciones al 20\% de lactosuero presentaron un comportamiento parecido al observado al usar las soluciones más concentradas de lactosuero en tiempos de secado de 4.5 y 5.0 h. En relación a la densidad, los mayores valores de este parámetro se obtuvieron en los materiales obtenidos al usar las soluciones más concentradas de lactosuero. El filme con mayor densidad se obtuvo al usar soluciones al $40 \%$ de lactosuero y al $2 \%$ de quitosano, y tiempo de secado de $4.5 \mathrm{~h}$, obteniéndose un material con densidad de $0.14 \mathrm{~g} / \mathrm{cm}^{3}$. 


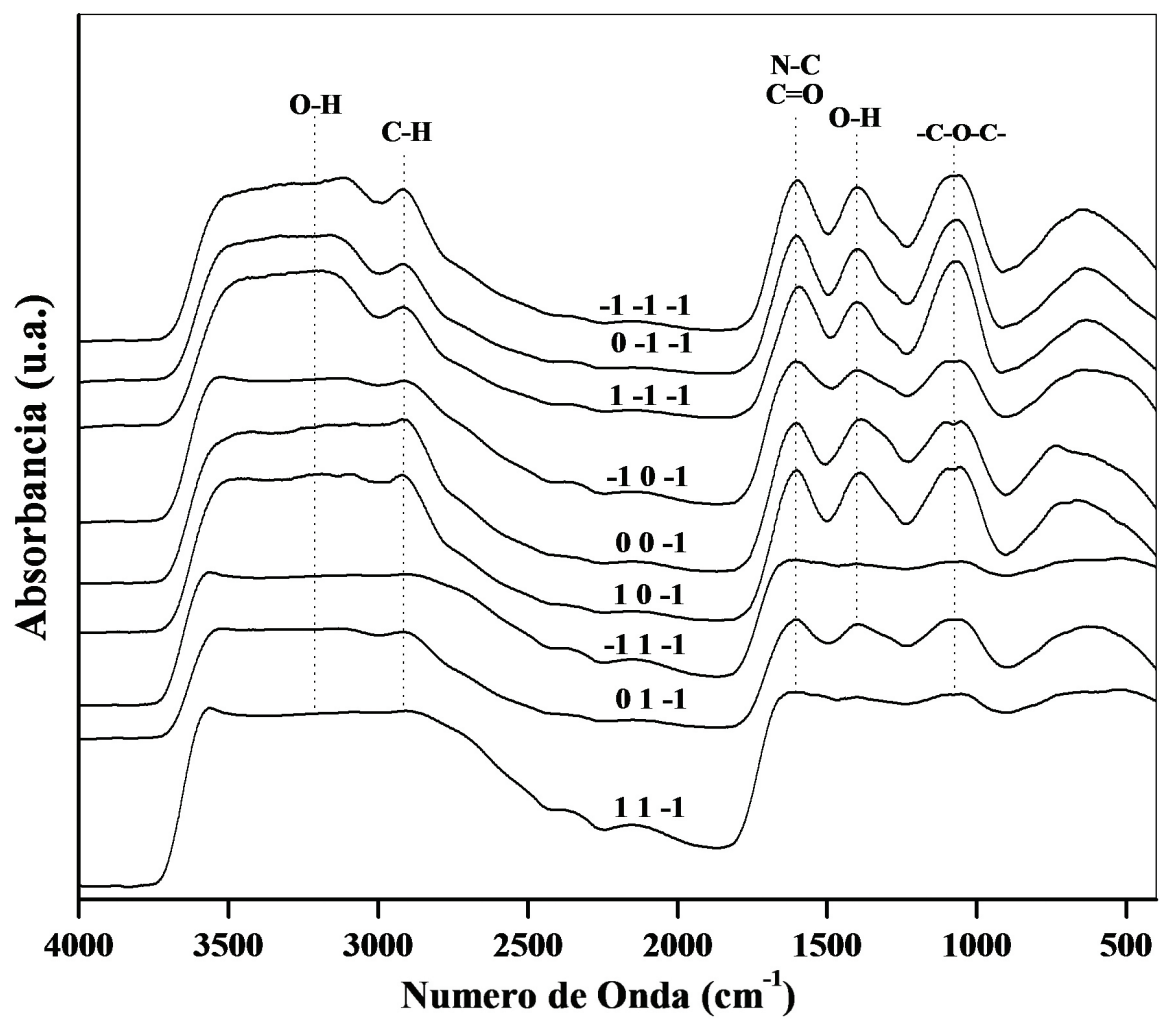

Figura 3. Espectros de infrarrojo de los filmes quitosano/lactosuero, obtenidos en el tiempo de secado de $4.5 \mathrm{~h}$ (nivel -1). Los valores de los niveles corresponden al porcentaje de quitosano, proporción de lactosuero y tiempo de secado, los cuales son mostrados en las Tablas 1 y 2 .

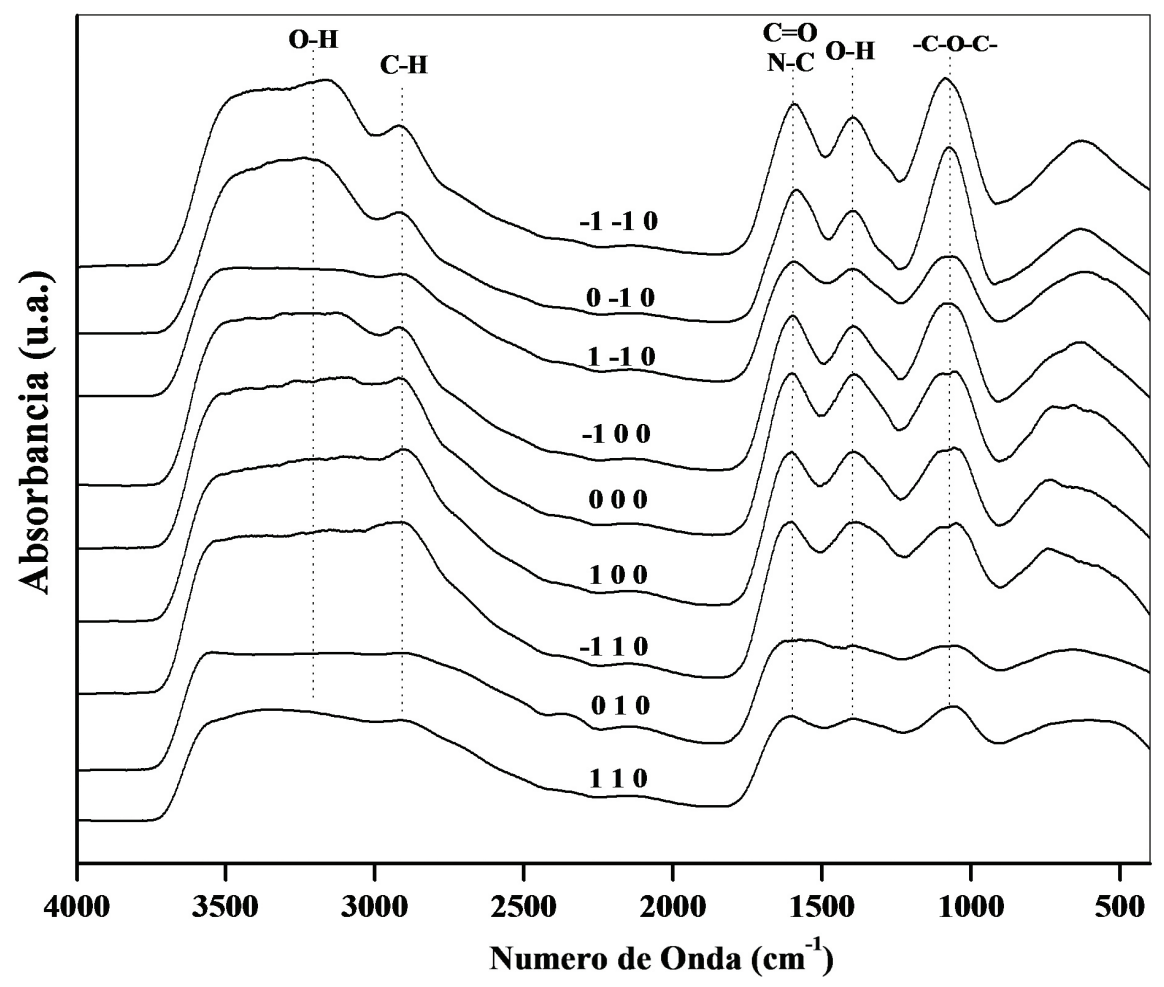

Figura 4. Espectros de infrarrojo de los filmes quitosano/lactosuero, obtenidos en el tiempo de secado de $5.0 \mathrm{~h}$ (nivel 0 ). Los valores de los niveles corresponden al porcentaje de quitosano, proporción de lactosuero y tiempo de secado, los cuales son mostrados en las Tablas 1 y 2. 


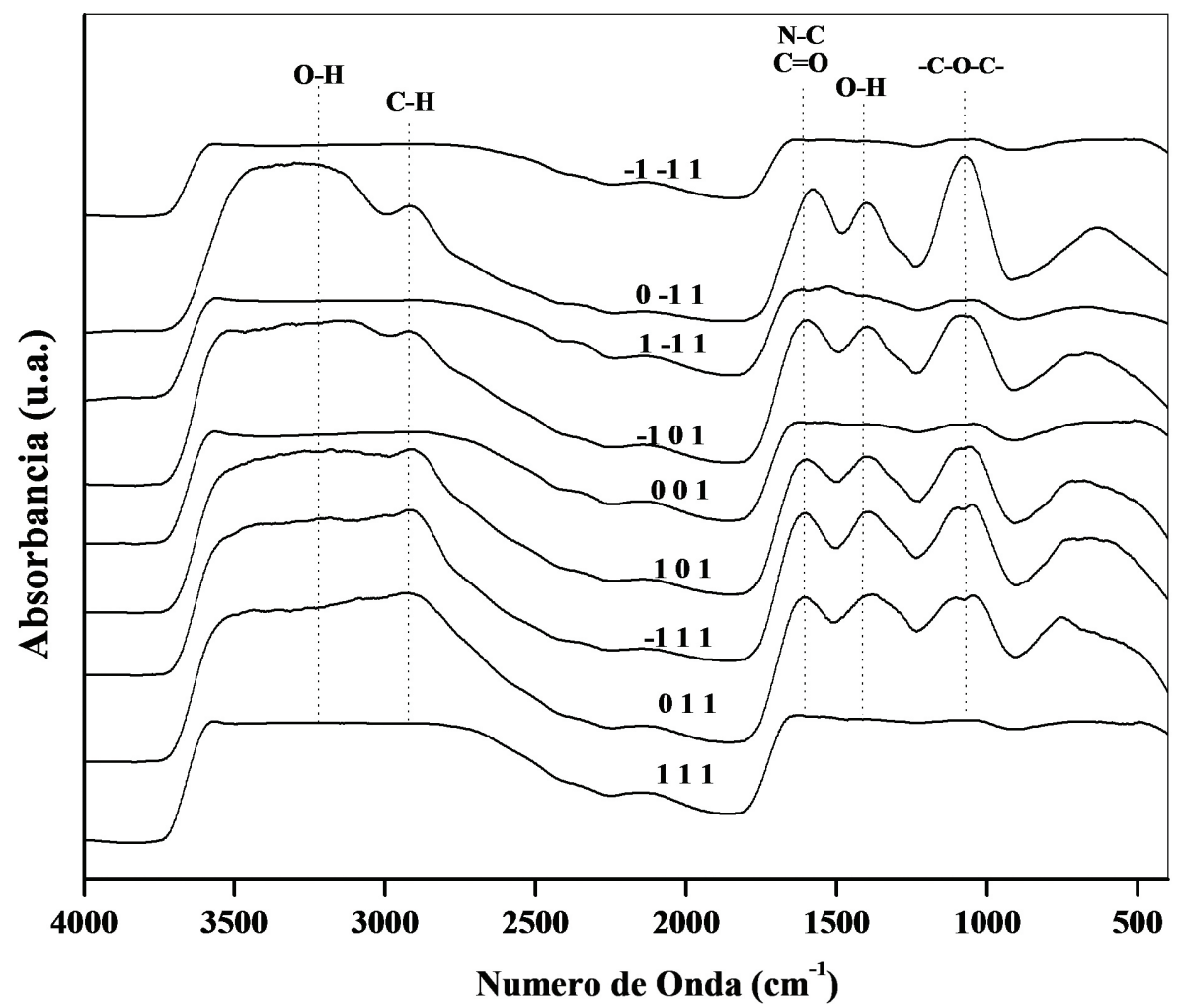

Figura 5. Espectros de infrarrojo de los filmes quitosano/lactosuero, obtenidos en el tiempo de secado de $5.5 \mathrm{~h}$ (nivel 1 ). Los valores de los niveles corresponden al porcentaje de quitosano, proporción de lactosuero y tiempo de secado, los cuales son mostrados en las Tablas 1 y 2.

\subsection{Solubilidad}

En este caso se utilizó la solubilidad como una medida de la integridad de las filmes en un medio acuoso, generalmente, mayor solubilidad indica menor resistencia al agua. Esta propiedad afecta la futura aplicación de las filmes; por ejemplo, las cubiertas aplicadas sobre los alimentos de alta humedad deben ser insolubles, mientras en otras aplicaciones estas deben disolverse fácilmente ${ }^{[20]}$. El mayor porcentaje de solubilidad en agua para los filmes quitosano/lactosuero se obtuvo en el tratamiento con $1,5 \%$ de quitosano (Figura 7 ), proporción de lactosuero de $30 \%$ y 4.5 h de secado (24.6\%). El menor porcentaje de solubilidad se observó con concentración de quitosano 1.5, proporción de lactosuero 40\% y 5 horas de secado (7.03\%). De acuerdo al análisis estadístico, la concentración de quitosano fue el principal factor que influyó en la variación de los niveles de solubilidad, a medida que se incrementa la concentración de quitosano la solubilidad de los filmes disminuye notablemente.

\subsection{Hinchamiento}

El índice de hinchamiento depende del peso molecular y grado de desacetilación del quitosano. Cabría esperar un aumento en el índice de hinchamiento al aumentar el grado de desacetilación ya que el contenido del grupo amino sería mayor. Las cadenas de quitosano presentan grupos hidrófilos como $-\mathrm{NH}_{2}$, lo que le confiere una alta afinidad hacia el agua. El porcentaje promedio de hinchamiento de los filmes elaborados varió en intervalo de 11.24 a $62.40 \%$. Este parámetro revela el nivel de absorción de agua de los filmes y según Di Pierro et al. ${ }^{[21]}$, el grado de hinchamiento de los materiales poliméricos depende en gran medida de la cantidad y la naturaleza de las interacciones intermoleculares de la cadena. El mayor valor se presentó en el tratamiento 10 (Tabla 2), un filme preparado con $1.5 \%$ de quitosano, proporción de lactosuero $20 \%$ y tiempo de secado de 4.5 horas, mientras que el menor valor de hinchamiento se presentó en el tratamiento 1, un filme elaborado con $1 \%$ de quitosano, proporción de lactosuero $20 \%$, tiempo de secado de 4.5 horas. Este comportamiento podría ser debido en parte a que los puentes de hidrógeno intramoleculares que se establecen entre los grupos hidroxilo y los grupos amino son mucho más fuertes que los que se establecen entre estos grupos polares y el agua ${ }^{[22]}$, lo cual contribuye con el hinchamiento, sin embargo otros factores como el diámetro y la solubilidad de los filmes también pueden contribuir en parte con el hinchamiento de los materiales. El hinchamiento de los filmes de quitosano puro preparados a condiciones ambientales es de alrededor de $173 \%{ }^{[23]}$, sin embargo en este estudio el valor se reduce notablemente; se ha observado que los métodos de secado pueden afectar el grado de hinchamiento de los filmes, por lo general el tratamiento térmico de quitosano lleva a la formación de un grupo amida, lo que puede reducir el número de grupos hidrofílicos y la consecuente disminución del hinchamiento de los filmes ${ }^{[24]}$. 


\subsection{Degradación}

El ensayo de degradación para los filmes quitosano/lactosuero se llevó a cabo simulando las condiciones planteadas en la NTC 1027, mediante la cual se evalúa el nivel de resistencia y degradación de los materiales plásticos en agua. La resistencia al agua es una propiedad importante de degradación de los filmes para aplicaciones como la protección de alimentos donde la actividad del agua es alta $^{[25]}$.

En la Figura 8 se observa el porcentaje de degradación de cada tratamiento después de 15, 30 y 45 días. El menor porcentaje promedio de degradación registrado en los

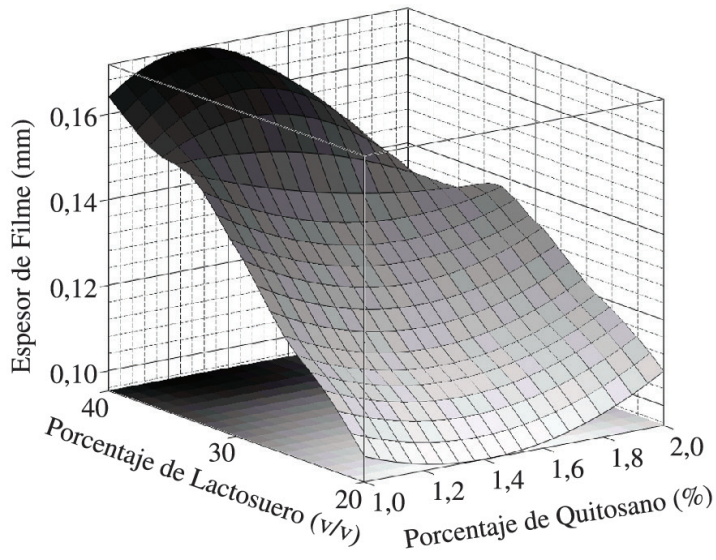

(a)

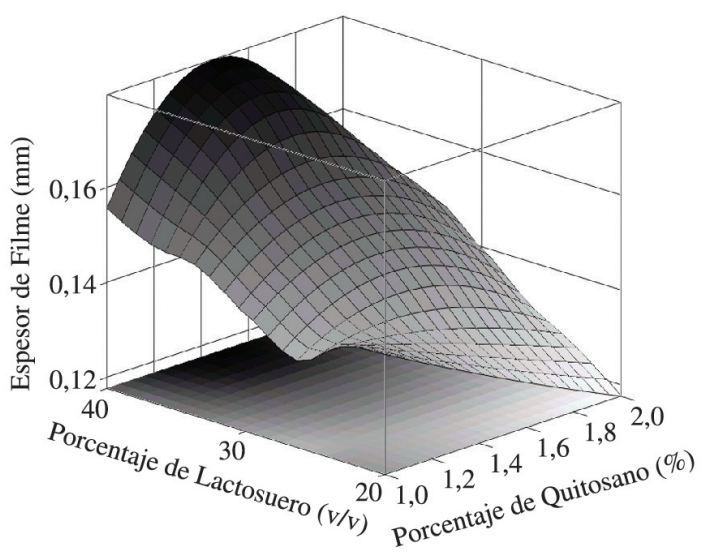

(b)

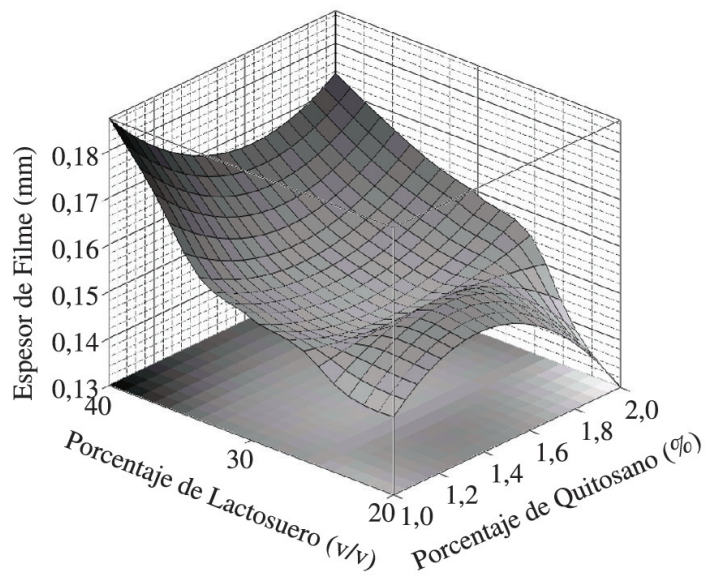

(c)

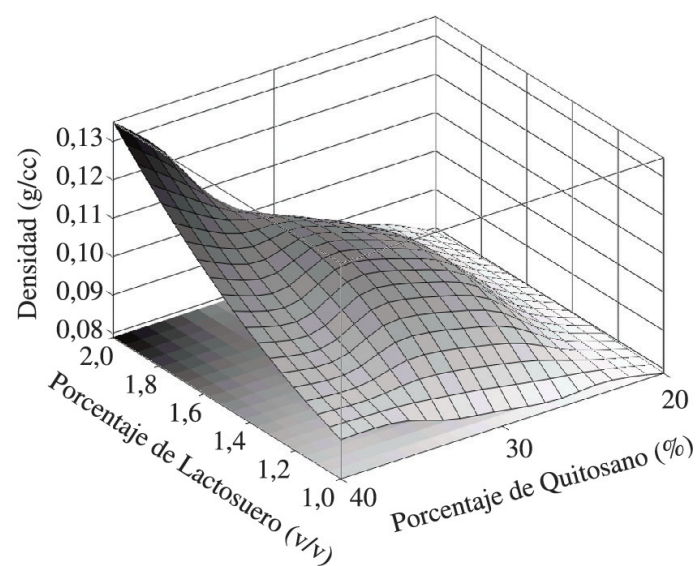

(d)

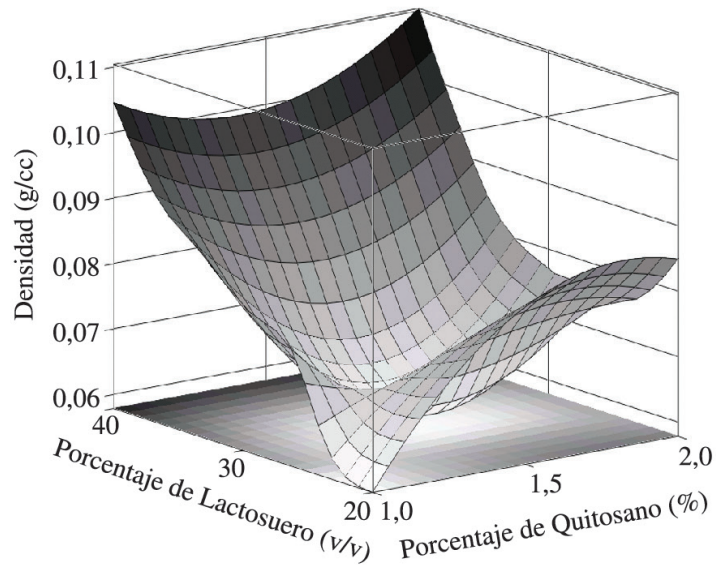

(e)

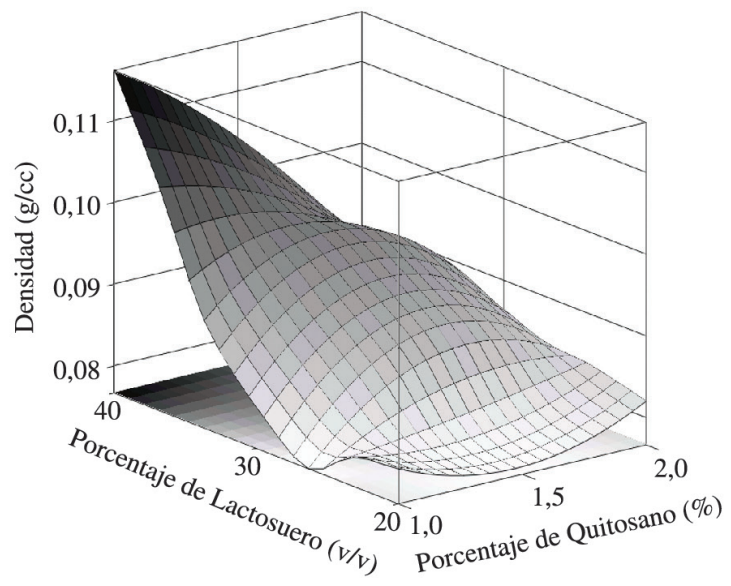

(f)

Figura 6. Superficies de respuesta del espesor y la densidad de los filmes en función de los porcentajes de lactosuero y de quitosano, obtenidos por secado a $4.5 \mathrm{~h}(\mathrm{a}, \mathrm{d}), 5.0 \mathrm{~h}(\mathrm{~b}, \mathrm{e})$ y $5,5 \mathrm{~h}(\mathrm{c}, \mathrm{f})$. 
filmes a los 45 días fue de $29.68 \%$ para el tratamiento con concentración de quitosano $2 \%$, proporción de lactosuero $20 \%$ y 4.5 horas de secado. El porcentaje promedio de mayor degradación fue de $60.66 \%$, que se presentó en el tratamiento a concentración de quitosano $1 \%$, proporción de lactosuero $30 \%$ y 5.5 horas de secado.

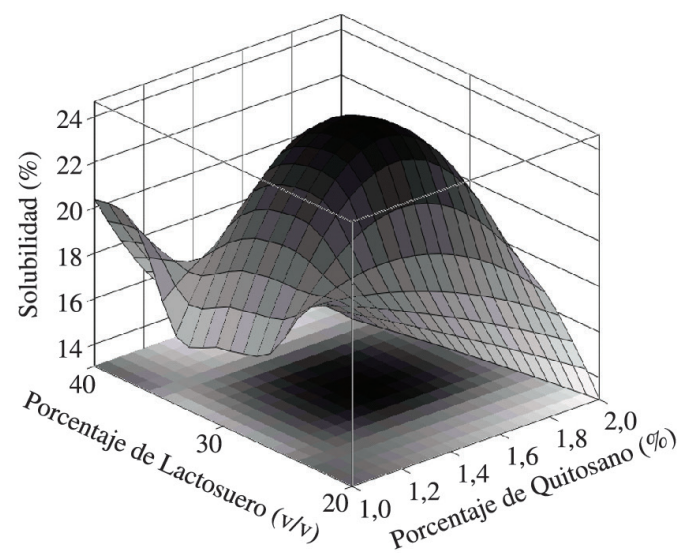

(a)

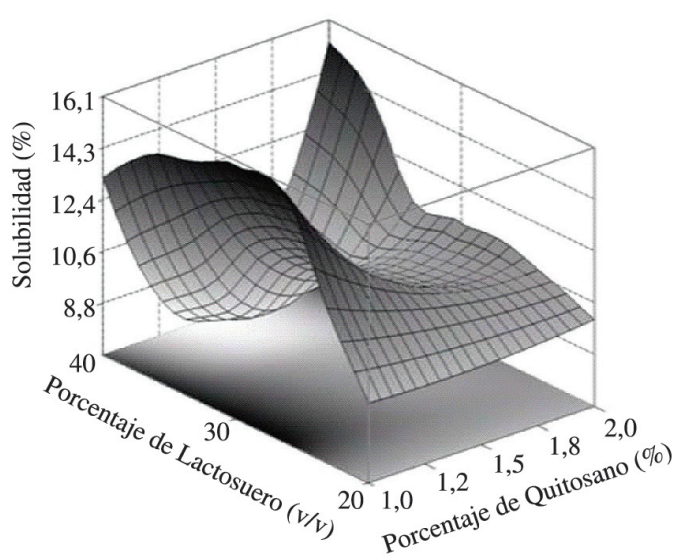

(b)

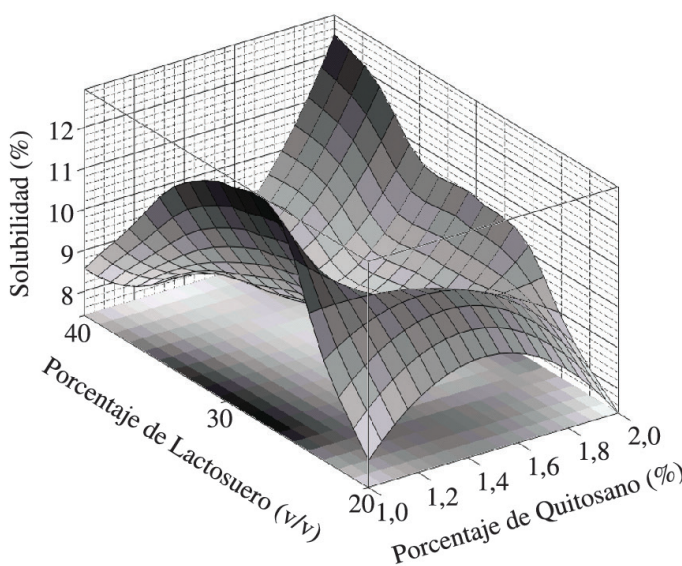

(c)
El análisis de varianza mostró diferencias estadísticamente significativas $(\mathrm{P}=0.0000)$ solo para el efecto de la concentración de quitosano sobre el nivel de degradación en agua. Se observa en la Figura 9 la influencia de la concentración de quitosano sobre el porcentaje de degradación. Se puede evidenciar que a concentraciones

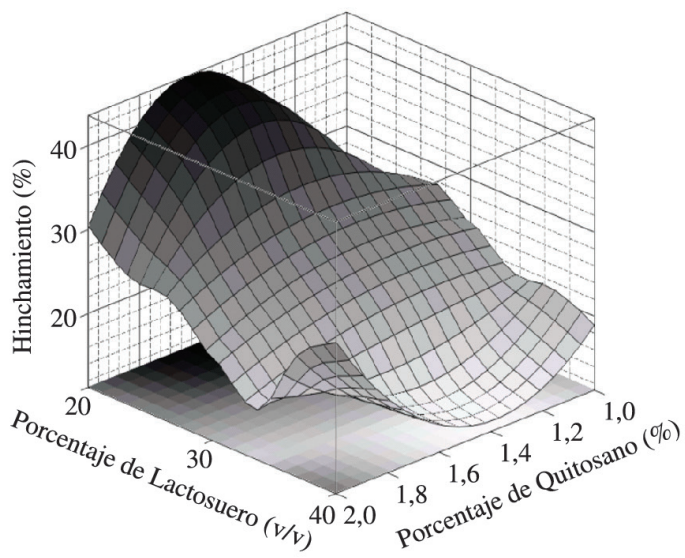

(d)

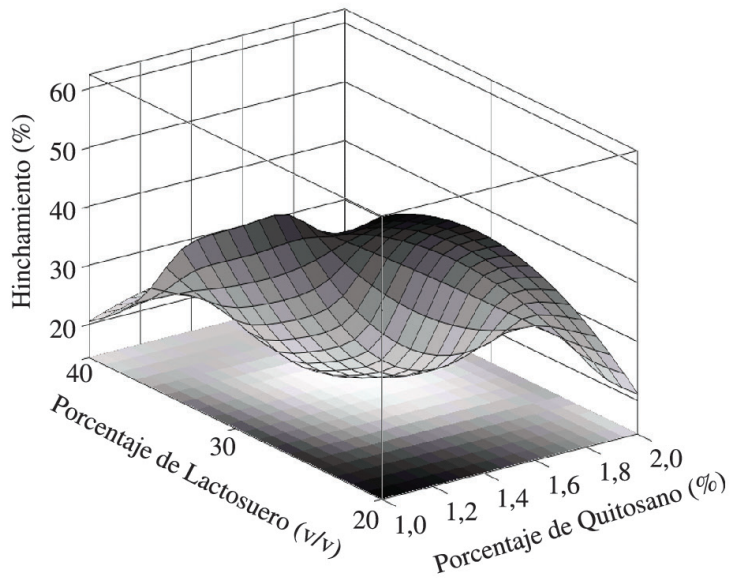

(e)

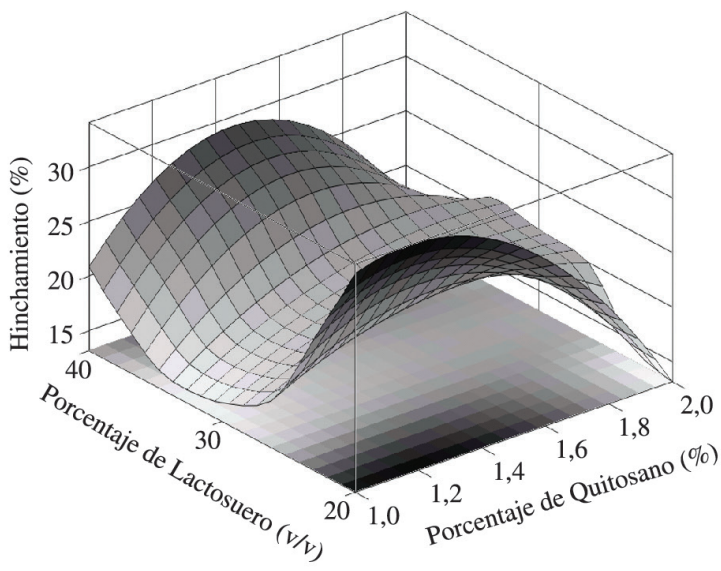

(f)

Figura 7. Superficies de respuesta de la solubilidad y del hinchamiento de los filmes en función de los porcentajes de lactosuero y de quitosano, obtenidos por secado a $4.5 \mathrm{~h}(\mathrm{a}, \mathrm{d}), 5.0 \mathrm{~h}(\mathrm{~b}, \mathrm{e})$ y $5,5 \mathrm{~h}(\mathrm{c}, \mathrm{f})$. 
de quitosano de $1 \%$, la degradación de los filmes es superior al $50 \%$, mientras que para los filmes preparados a concentraciones de $2 \%$ el porcentaje de degradación es menor; esto se debe a que al haber una mayor concentración de quitosano el proceso de degradación es más lento.

Filmes comestibles compuestos por lactosuero han sido reportados anteriormente, los cuales se caracterizan por ser transparentes, proporcionar ciertas propiedades mecánicas ${ }^{[26]}$ y como características muy importantes ser enteramente biodegradables y muy usados en varios tipos de alimentos. Sashiwa et al. ${ }^{[27]}$ estudiaron las tasas relativas de la degradación de seis tipos de quitosano con diferentes grados de desacetilación ( $45 \%, 66 \%, 70 \%, 84 \%$, $91 \%$ y $95 \%$ ), e informaron que el quitosano con $70 \%$ de desacetilación se degrada más rápidamente.

En la Figura 10 se observan los espectros de infrarrojo de un filme antes y después de la prueba de degradación. En general, el espectro obtenido después de la prueba de degradación revela un leve aumento en la transmitancia de los grupos funcionales presentes en la composición química del filme y un cambio en los picos observados. La banda que se localizaba en la región comprendida entre $3520-2866 \mathrm{~cm}^{-1}$ se ve un poco desplazada a la región $3560-2880 \mathrm{~cm}^{-1}$.

La desaparición de grupos funcionales al romperse enlaces presentes en la estructura, producto de la degradación del filme se ve evidenciada en la Figura10b, en la cual el pico original a $2360 \mathrm{~cm}^{-1}$ desaparece por completo. Así mismo el desplazamiento y la elongación un tanto más pronunciada de los picos originales 2140, 1640 y $1080 \mathrm{~cm}^{-1}$ (Figura 10a) hacia las regiones de 2145, $1636 \mathrm{y}$ $1081 \mathrm{~cm}^{-1}$ (Figura 10b) está influenciado por la ruptura de enlaces y perdida de átomos en la estructura química del filme. Se observó en la mayoría de los casos que la mayor degradación aumenta con el tiempo de exposición de los filmes, producto de la desnaturalización de las proteínas y otros componentes de los sólidos o en algunos casos la agregación reversible de proteínas y a la auto-asociación de polisacáridos presentes en los materiales.

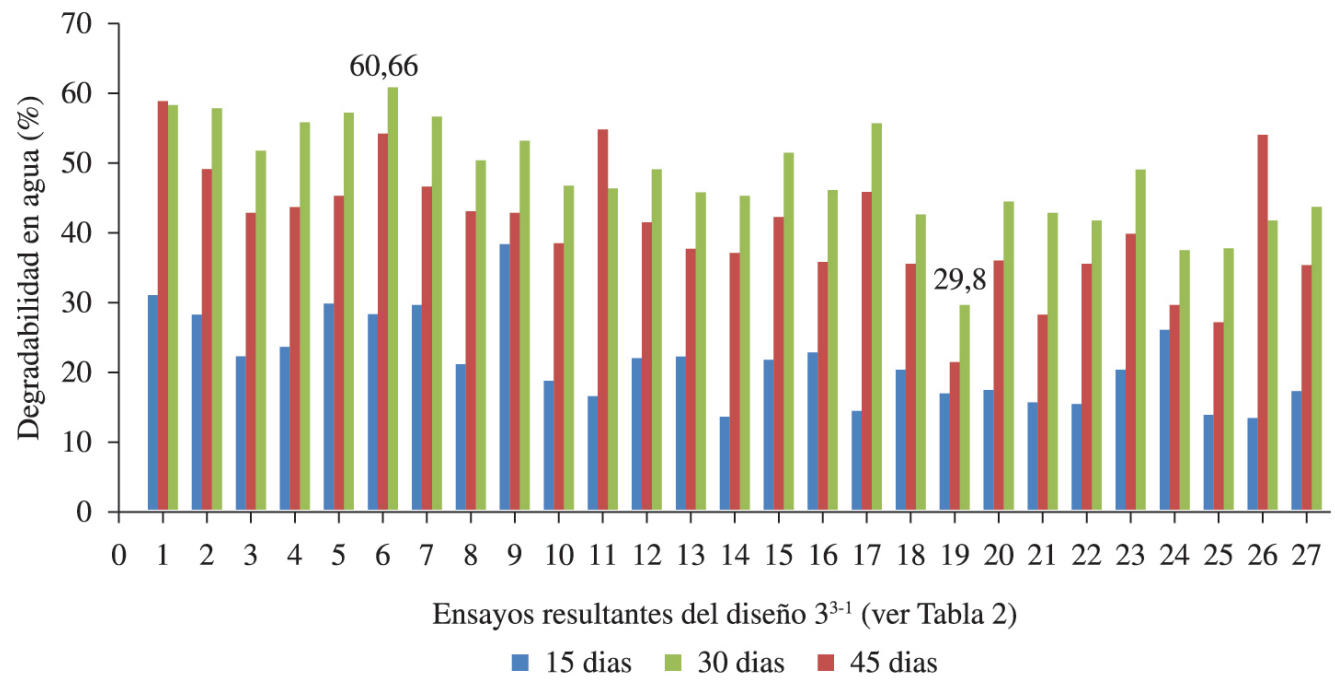

Figura 8. Porcentaje de degradación en agua de los tratamientos a 15, 30 y 45 días.

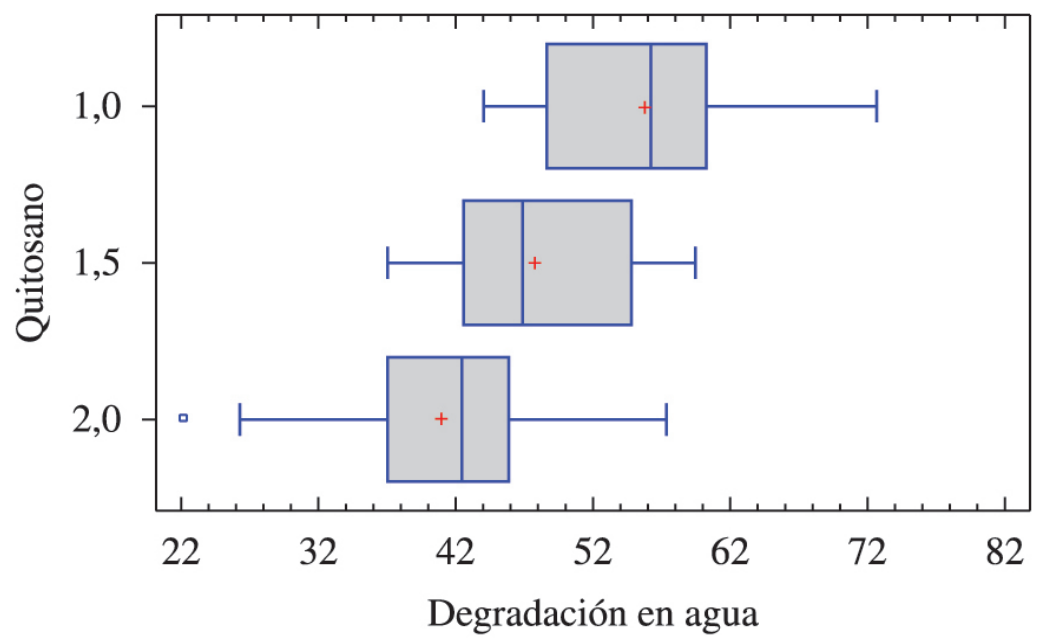

Figura 9. Efecto de la concentración de quitosano sobre la degradación. 


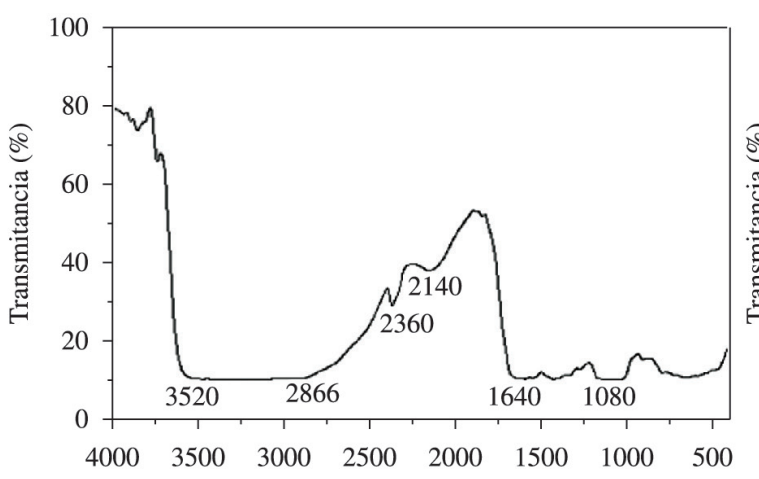

Numero de onda $\left(\mathrm{cm}^{-1}\right)$

(a)

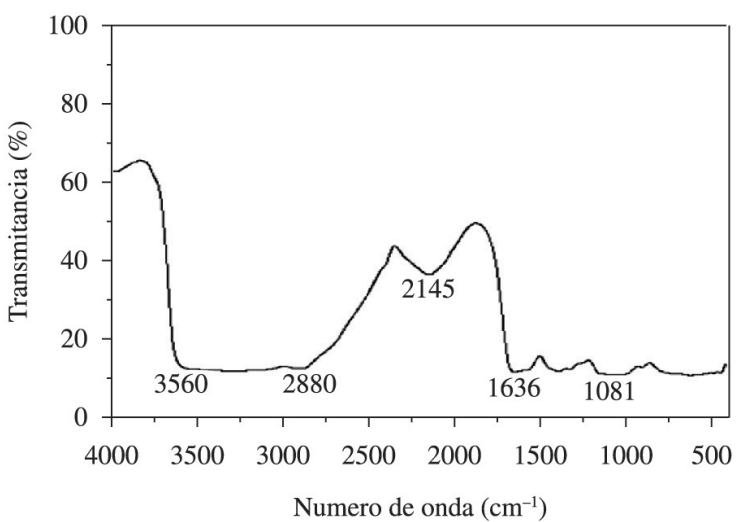

(b)

Figura 10. Espectros infrarrojo de filmes quitosano-lactosuero preparado a concentración de quitosano $2 \%$, proporción de lactosuero 0.3 y 5 horas de secado. a) Espectro IR antes de la prueba de degradación. b) Espectro IR después de prueba de degradación.

\section{Conclusiones}

La obtención de quitosano con un grado de desacetilación de $80.72 \%$ indica que la metodología y el tratamiento químico aplicado en este estudio son convenientes para la obtención de un producto final dentro de los niveles estándares. Los niveles de hinchamiento de los filmes quitosano/lactosuero son menores (porcentajes promedios menores de 63\%) en comparación con los de filmes preparados con quitosano puro indicando una aumento en la hidrofobicidad. Las proporciones de lactosuero incorporadas a los filmes de quitosano tienen efecto significativo en el aumento del espesor y la densidad. Los filmes mostraron una baja solubilidad en agua, siendo mayor para los preparados a concentraciones de quitosano de $1 \%$. La evaluación de la degradación en agua de los filmes quitosano/lactosuero revela que a concentraciones altas de quitosano (superiores a $1.5 \%$ ) los filmes son más resistentes a la degradación presentando porcentajes inferiores al 50\% durante un periodo de prueba de 45 días.

\section{Referencias}

1. Miranda, S. P., Cárdenas, G., López, D., \& Sagahon, A. V. L. (2003). Comportamento de películas de quitosán compuesto en un modelo de almacenamiento de aguacate. Journal of the Mexican Chemical Society, 47(4), 331-336.

2. Kirk, R., \& Othmer, D. F. (1970). Enciclopedia de Tecnología Química (1st ed.). México: Hispano Americana.

3. Alvarado, J., Arancibia, M., \& Almeida, A. (2005). Desarrollo y Caracterización de Películas de Quitosano. Revista de Ciencia y Tecnología, 4(2), 39-47.

4. Rotta, J., Ozório, R. A., Kehrwald, A. M., Barra, G. M. O., Amboni, R. D. M. C., \& Barreto, P. L. M. (2009). Parameters of color, transparency, water solubility, wettability and surface free energy of chitosan/hydroxypropylmethylcellulose (HPMC) films plasticized with sorbitol. Materials Science and Engineering, 29(2), 619-623. http://dx.doi.org/10.1016/j. msec.2008.10.032

5. Aider, M., Halleux, D., \& Melnikova, I. (2009). Skim acidic milk whey cryoconcentration and assessment of its functional properties: Impact of processing conditions. Innovative Food
Science \& Emerging Technologies, 10(3), 334-341. http:// dx.doi.org/10.1016/j.ifset.2009.01.005.

6. Dash, M., Chiellini, F., Fernandez, E. G., Piras, A. M., \& Chiellini, E. (2011). Statistical approach to the spectroscopic determination of the deacetylation degree of chitins and chitosans. Carbohydrate Polymers, 86, 65-71.

7. Baxter, A., Dillon, M., Taylor, K. D. A., \& Roberts, G. A. F. (1992). Improved method for i.r. determination of the degree of $\mathrm{N}$-acetylation of chitosan. International Journal of Biological Macromolecules, 14(3), 166-169. http://dx.doi.org/10.1016/ S0141-8130(05)80007-8. PMid:1390449

8. Gontard, N., Guilbert, S., \& Cuq, J. (1992). Edible Wheat Gluten Films: Influence of the Main Process Variables on Film Properties using Response Surface Methodology. Journal of Food Science, 57(1), 190-195. http://dx.doi. org/10.1111/j.1365-2621.1992.tb05453.x.

9. Wu, J., Zhong, F., Li, Y., Shoemaker, C. F., \& Xia, W. (2013). Preparation and characterization of pullulan-chitosan and pullulan-carboxymethyl chitosan blended films. Food Hydrocolloids, 30(1), 82-91. http://dx.doi.org/10.1016/j. foodhyd.2012.04.002.

10. Jia, D., Fang, Y., \& Yao, K. (2009). Water vapor barrier and mechanical properties of konjac glucomannan-chitosan-soy protein isolate edible films. Food and Bioproducts Processing, 87(1), 7-10. http://dx.doi.org/10.1016/j.fbp.2008.06.002.

11. Instituto Colombiano de Normas Técnicas y Certificación. (2001). Norma Técnica Colombiana NTC No. 1027: Plásticos. Determinación de los efectos de productos químicos líquidos, incluyendo el agua en los materiales plásticos. Bogotá: ICONTEC.

12. Cocoletzi, H. H., Almanza, E. Á., Augustin, O. F., Nava, E. L. V., \& Casselis, E. R. (2009). Obtención y caracterización de quitosano a partir de exoesqueletos de camarón. Superficies y Vacío, 22(3), 57-60.

13. Rodriguez, W., Gomez, C. A., Castro, J., Gonzalez, C. A., \& Santos, E. M. (2010). Caracterización Fisicoquimica del Lactosero en el Valle de Tucilango. In XII Congreso Nacional de Ciencia y Tecnologia de Alimentos (pp. 327). Guanajuato: Universidad de Guanajuato.

14. Gerasimenko, D., Avdienko, I. D., Bannikova, G. E., Zueva, O. Y., \& Varlamov, V. P. (2004). Antibacterial Effects of Water-Soluble Low-Molecular-Weight Chitosans on Different Microorganisms. Applied Biochemistry and Microbiology, 40(3), 253-257. http://dx.doi.or g/10.1023/B:ABIM.0000025947.84650.b4. 
15. Ferreira, C. O., Nunes, C. A., Delgadillo, I., \& Lopes-da-Silva, J. A. (2009). Characterization of chitosan-whey protein films at acid pH. Food Research International, 42(7), 807-813. http:// dx.doi.org/10.1016/j.foodres.2009.03.005.

16. Pawlak, A., \& Mucha, M. (2003). Thermogravimetric and FTIR studies of chitosan blends. Thermochimica Acta, 396(1-2), 153-166. http://dx.doi.org/10.1016/S0040-6031(02)00523-3.

17. Wang, J., Van Apeldoorn, A., \& Groot, K. (2004). Electrolytic deposition of calcium phosphate/chitosan coating on titanium alloy: growth kinetics and influence of current density, acetic acid, and chitosan. Journal of Biomedical Materials Research. Part A, 76(3), 503-511.

18. Roblejo, J. (2009). Evaluación de la Aplicación de Coberturas de Quitosana en la Conservación de Tomates (Tesis de Pregrado). Universidad de la Habana, Instituto de Farmacia y Alimentos, La Habana.

19. Butler, B. L., Vergano, P. J., Testin, R. F., Bunn, J. M., \& Wills, J. L. (1996). Mechanical and Barrier Properties of Edible Chitosan Films as affected by Composition and Storage. Journal of Food Science, 61(5), 953-956. http://dx.doi. org/10.1111/j.1365-2621.1996.tb10909.x.

20. Sothornvit, R., \& Krochta, J. M. (2000). Water Vapor Permeability and Solubility of Films from Hydrolyzed Whey Protein. Journal of Food Science, 65(4), 700-703. http://dx.doi. org/10.1111/j.1365-2621.2000.tb16075.x.

21. Di Pierro, P., Chico, B., Villalonga, R., Mariniello, L., Damiao, A., Masi, P., \& Porta, R. (2006). Chitosan-Whey Protein Edible Films Produced in the Absence or Presence of Transglutaminase: Analysis of Their Mechanical and Barrier Properties. Biomacromol., 7(3), 744-749. http://dx.doi. $\operatorname{org} / 10.1021 / \mathrm{bm} 050661 \mathrm{u}$.
22. Vílchez, S. (2005). Nuevos Tratamientos de Lana con Enzimas (Tesis de Doctorado). Universidad de Barcelona, Barcelona.

23. Yao, K. D., Peng, T., Yin, Y. J., Xu, M. X., \& Goosen, M. F. A. (1995). Microcapsules/Microspheres Related to Chitosan. Journal of Macromolecular Science, Part C: Polymer Reviews, 35(1), 155-180. http://dx.doi. org/10.1080/15321799508014592.

24. Muzzarelli, R. A. A., \& Rochetti, R. (1985). Determination of the degree of acetylation of chitosans by first derivative ultraviolet spectrophotometry. Carbohydrate Polymers, 5(6), 461-472. http://dx.doi.org/10.1016/0144-8617(85)90005-0.

25. Rotta, J., Ozório, R. Á., Kehrwald, A. M., de Oliveira Barra, G. M., de Melo Castanho Amboni, R. D., \& Barreto, P. L. M. (2009). Parameters of color, transparency, water solubility, wettability and surface free energy of chitosan/ hydroxypropylmethylcellulose (HPMC) films plasticized with sorbitol. Materials Science and Engineering, 29(2), 619-623. http://dx.doi.org/10.1016/j.msec.2008.10.032.

26. Sothornvit, R., Rhim, J.-W., \& Hong, S.-I. (2009). Effect of nano-clay type on the physical and antimicrobial properties of whey protein isolate/clay composite films. Journal of Food Engineering, 91(3), 468-473. http://dx.doi.org/10.1016/j. jfoodeng.2008.09.026.

27. Sashiwa, H., Saimoto, H., Shigemasa, Y., Ogawa, R., \& Tokura, S. (1990). Lysozyme susceptibility of partially deacetylated chitin. International Journal of Biological Macromolecules, 12(5), 295-296. http://dx.doi. org/10.1016/0141-8130(90)90016-4. PMid:2085495

Enviado: Sept. 18, 2013

Reenviado: Jun. 05, 2014 Aceptado: Jul. 10, 2014 